\title{
Comunicação
}

[Communication]

\section{Método da espectroscopia no infravermelho para análise dos soros de queijos de minas padrão e prato}

\author{
[Infrared spectroscopy method to measure the whey composition in \\ "minas padrão" and "prato" cheeses] \\ F.A. Pinto ${ }^{1}$, L.M. Fonseca ${ }^{2 *}$, L.R. Abreu ${ }^{3}$, M.R. Souza ${ }^{2}$, D.L.S. Oliveira ${ }^{1}$, \\ L.A. Clementino ${ }^{4}$, E.H.P. Andrade $e^{1}$
}
${ }^{1}$ Aluna de pós-graduação - Escola de Veterinária -Universidade Federal de Minas Gerais - UFMG - Belo Horizonte, MG
${ }^{2}$ Departamento de Tecnologia e Inspeção de Produtos de Origem Animal - Escola de Veterinária - UFMG
Caixa Postal 567
31270-901 - Belo Horizonte, MG
${ }^{3}$ Departamento de Tecnologia de Alimentos, Universidade Federal de Lavras - Lavras, MG
${ }^{4}$ Aluna de graduação - Escola de Veterinária - UFMG - Belo Horizonte, MG

Existem poucos estudos sobre as características físico-químicas do soro de leite produzido no Brasil. Dentre esses trabalhos, pode ser citado o realizado por Teixeira et al. (2008), que enfatizaram a importância desse tipo de análise no fornecimento de dados para o melhor aproveitamento do soro. $\mathrm{O}$ crescimento da utilização do soro produzido no Brasil tem aumentado a demanda por análises das características físico-químicas desse produto. Para atender a essa demanda, é necessária a utilização de métodos rápidos e precisos. Para a análise físico-química, o uso de equipamentos eletrônicos baseados na espectroscopia no infravermelho (IV) é uma alternativa interessante, pois apresenta maior rapidez e precisão quando comparada às metodologias de referência (Silveira, 2002; Teixeira et al., 2008).

No Brasil, equipamentos que se baseiam na metodologia da espectroscopia no infravermelho são utilizados para a análise de composição do leite, porém, para análise de composição de soro, não foram encontrados relatos na literatura consultada sobre o assunto. Para que essa técnica seja validada, é necessário verificar se os equipamentos baseados na espectroscopia no IV podem analisar as amostras de soros de queijos

Recebido em 30 de maio de 2011

Aceito em 9 de junho de 2011

*Autor para correspondência (corresponding author)

E-mail: leorges@ufmg.br produzidos no Brasil de forma a se obter resultados precisos. O objetivo deste trabalho foi verificar se os resultados obtidos pelo método da espectroscopia no IV são equivalentes aos dos métodos de referência para análise da composição físico-química dos soros obtidos na produção de queijos de minas padrão e prato.

Foram coletadas 22 amostras de soro de queijo prato e 21 amostras de soro de queijo de minas padrão. As amostras foram provenientes de laticínios localizados em Lavras, MG, que apresentavam registro no Serviço de Inspeção Federal. As amostras, coletadas diretamente do tanque de produção de queijos, logo após o corte da massa, foram acondicionadas em recipientes plásticos e transportadas em caixas isotérmicas contendo gelo reciclável. O início das análises ocorreu em um prazo máximo de um dia após a coleta do soro. O período de coleta foi de agosto a dezembro de 2009.

As amostras de soro foram divididas em duas alíquotas, uma para análise por métodos de referência e outra para análise de composição em analisador eletrônico de IV baseado em filtros (Bentley..., 2007). As análises foram realizadas em duplicata: teores de umidade/sólidos totais pelo método de secagem em estufa (Official..., 
1997), gordura pelo método de Mojonnier (Official..., 1997), proteína total pelo método de micro-Kjeldahl (Official..., 1997) e crioscopia (Brasil, 2006).

A análise pela espectroscopia no IV foi feita por meio do equipamento Bentley 2000 (Bentley Instruments ${ }^{\circledR}$ ). Para a realização das análises, o aparelho foi calibrado, utilizando-se 10 amostraspadrão de soro de leite com diferentes faixas de composição, as quais foram fornecidas pelo laboratório DQCI Services (Dairy Quality Control Inc. - Dairy Quality Control Incorporated, Estados Unidos).
Os resultados de composição de cada componente, obtidos pelas metodologias testadas, foram pareados e testados para diferença significativa no nível de $\mathrm{P} \leq 0,05$, por meio do teste de Wilcoxon para diferenças entre pares ordenados. O programa estatístico usado foi o Minitab 15.0 para Windows (Minitab Inc., Filadélfia, EUA).

Os resultados das análises dos teores de gordura, proteína e sólidos totais obtidos pelos métodos de referência foram diferentes $(\mathrm{P} \leq 0,05)$ dos obtidos pelo método da espectroscopia no IV, tanto para a análise do soro de queijo de minas padrão quanto para o soro de queijo prato (Tab. 1).

Tabela 1. Composição dos soros de queijos de minas padrão e prato

\begin{tabular}{|c|c|c|c|c|c|c|c|c|c|}
\hline \multirow[b]{2}{*}{ Componente } & \multirow[b]{2}{*}{$\begin{array}{l}\text { Método de } \\
\text { análise }\end{array}$} & \multicolumn{4}{|c|}{ Soro de queijo de minas padrão } & \multicolumn{4}{|c|}{ Soro de queijo prato } \\
\hline & & Média & $\begin{array}{c}\text { Desvio- } \\
\text { padrão }\end{array}$ & Min. & Max. & Média & $\begin{array}{l}\text { Desvio- } \\
\text { Padrão }\end{array}$ & Min. & Max. \\
\hline \multirow{2}{*}{ Gordura $(\mathrm{g} / 100 \mathrm{~g})$} & \multirow{2}{*}{$\begin{array}{l}\text { Referência } \\
\text { Infravermelho }\end{array}$} & $0,38 \mathrm{a}$ & 0,12 & 0,20 & 0,62 & $0,40 \mathrm{a}$ & 0,08 & 0,27 & 0,63 \\
\hline & & $0,33 b$ & 0,12 & 0,23 & 0,67 & $0,26 \mathrm{~b}$ & 0,15 & 0,04 & 0,67 \\
\hline \multirow{2}{*}{ Proteína $(g / 100 g)$} & \multirow{2}{*}{$\begin{array}{l}\text { Referência } \\
\text { Infravermelho }\end{array}$} & $0,78 \mathrm{a}$ & 0,08 & 0,65 & 0,88 & $0,78 \mathrm{a}$ & 0,09 & 0,58 & 0,91 \\
\hline & & $0,67 \mathrm{~b}$ & 0,11 & 0,54 & 0,82 & $0,73 b$ & 0,07 & 0,58 & 0,81 \\
\hline \multirow{2}{*}{$\begin{array}{l}\text { Sólidos totais } \\
(\mathrm{g} / 100 \mathrm{~g})\end{array}$} & \multirow{2}{*}{$\begin{array}{l}\text { Referência } \\
\text { Infravermelho }\end{array}$} & $6,42 \mathrm{a}$ & 0,21 & 6,00 & 6,68 & $6,19 \mathrm{a}$ & 0,75 & 4,70 & 6,79 \\
\hline & & $6,79 b$ & 0,20 & 6,44 & 7,02 & $6,85 b$ & 0,54 & 5,53 & 7,00 \\
\hline \multirow{2}{*}{ Umidade $g / 100 \mathrm{~g}$} & \multirow{2}{*}{$\begin{array}{l}\text { Referência } \\
\text { Infravermelho }\end{array}$} & $93,58 \mathrm{a}$ & 0,21 & 93,32 & 94,01 & $93,81 \mathrm{a}$ & 0,75 & 93,21 & 95,31 \\
\hline & & $93,21 b$ & 0,21 & 92,98 & 93,57 & $93,15 b$ & 0,55 & 93,00 & 94,48 \\
\hline Cinzas $(\mathrm{g} / 100 \mathrm{~g})$ & Referência & 0,49 & 0,03 & 0,45 & 0,54 & 0,48 & 0,05 & 0,40 & 0,55 \\
\hline $\begin{array}{l}\text { Cloreto de sódio } \\
(\mathrm{g} / 100 \mathrm{~g})\end{array}$ & Referência & 0,20 & 0,01 & 0,18 & 0,21 & 0,19 & 0,02 & 0,15 & 0,21 \\
\hline $\begin{array}{l}\text { Índice crioscópico } \\
\left({ }^{\circ} \mathrm{C}\right)\end{array}$ & Referência & $-0,507$ & 0,01 & $-0,526$ & $-0,493$ & $-0,492$ & 0,05 & $-0,516$ & $-0,400$ \\
\hline
\end{tabular}

Para cada componente e tipo de soro, resultados com letras distintas, na mesma coluna, indicam diferença significativa $(\mathrm{P}<0,05)$.

As amostras-padrão utilizadas na calibração do equipamento baseado na espectroscopia no IV eram constituídas de soro cru, sendo este o único padrão de calibração disponível comercialmente no mercado mundial. Em contrapartida, as amostras de soro de queijos de minas padrão e prato eram pasteurizadas.

As alterações promovidas pela pasteurização nas moléculas dos componentes do soro podem afetar a frequência vibracional dessas moléculas. Essa frequência é a base da metodologia da espectroscopia no IV. A análise por meio de tal metodologia baseia-se na absorção da radiação pelos grupos químicos da gordura, proteína e lactose. Uma molécula é capaz de absorver esta radiação apenas quando ela apresenta a mesma frequência de vibração da radiação (Biggs et al., 1987; Bouis, 1997). Assim, se a frequência vibracional da molécula for alterada, a absorção da radiação por essa molécula também sofrerá alterações, o que poderá comprometer os resultados. 
A adição de água é outro fator que pode ter influenciado a análise pela metodologia baseada na espectroscopia no IV. A água apresenta intensa banda de absorção da radiação infravermelha centrada no comprimento de onda de $6,1 \mu \mathrm{m}$. A intensidade da banda de absorção da água faz com que ela se sobreponha às bandas de absorção características das proteínas que estão entre os comprimentos de onda $6,3 \mu \mathrm{m}$ e $5,9 \mu \mathrm{m}$ (Etzion et al., 2004). Esse fato pode gerar resultados alterados, principalmente para o soro de queijo prato, pois algumas amostras deste soro continham adição de água, fato evidenciado pelo seu índice crioscópico, isto é, ponto de congelamento se aproximando de $0^{\circ} \mathrm{C}$ (Tab. 1).

O corante urucum, utilizado na produção do queijo prato, também pode ser um interferente na análise do soro. O urucum é constituído, basicamente, de dois carotenoides: cis-bixina e a norbixina (Silva, 2007). Souza (2000), ao realizar análises espectrais dos componentes químicos do urucum, verificou que, no intervalo entre $5,7 \mu \mathrm{m}$ e $6,3 \mu \mathrm{m}$ e entre $2,8 \mu \mathrm{m}$ e $3,5 \mu \mathrm{m}$, há uma absorção forte da radiação infravermelha pelos grupos químicos da bixina e da norbixina. As bandas de absorção desses grupos químicos coincidem com as bandas de absorção da proteína e gordura. Isso pode ter interferido na análise destes componentes.

A calibração do equipamento é também um fator que interfere na análise pela espectroscopia no IV. Existem dois tipos de calibração: por dados não corrigidos e por dados corrigidos (Bentley..., 2007). A calibração por dados não corrigidos é realizada somente após manutenções importantes do equipamento, e recomenda-se que seja feita por técnico especializado. Por outro lado, a calibração por dados corrigidos é realizada pelo próprio operador do equipamento e deve ser feita rotineiramente para garantir a acuidade dos resultados. A calibração usada no presente trabalho foi a de dados corrigidos. Entretanto, devido a não linearidade do modelo obtido, fato ocorrido em função do tipo de calibração utilizado, os resultados foram transformados, simulando a calibração por dados não corrigidos, e submetidos à análise estatística (teste de Wilcoxon). Para o soro de queijo de minas padrão, os resultados transformados foram estatisticamente semelhantes aos dos métodos de referência. Entretanto, para o soro de queijo prato, a linearização do modelo não foi suficiente para a equivalência dos métodos. Nesse tipo de soro, a presença de corante e o excesso de água adicionada durante o processamento da massa do queijo, etapas inexistentes na fabricação do queijo de minas padrão, podem ter contribuído para a manutenção dessa diferença.

Conclui-se que a espectroscopia no IV, baseada em filtros, pode ser utilizada na análise da composição físico-química do soro de queijo de minas padrão, contanto que seja feita uma calibração com dados não corrigidos específica para este produto. Houve imprecisão desse tipo de metodologia para a análise de soro de queijo prato.

Palavras-chave: soro de queijo, composição, espectroscopia no IV

\begin{abstract}
An electronic equipment based on the infrared spectroscopy was evaluated to measure the whey composition in "Minas padrão" and "prato" cheeses. The results for fat, protein, and total solids using infrared instrument based on filters and using standard methods were compared. There were differences between the values obtained from both analytical methods, and since compounds formed during heating of the analyzed whey may have interfered with infrared spectrum readings, a linear transformation of the data was done. After this statistical adjustment, results for "Minas padrão" cheese were equivalent in both infrared and standard methods. For "prato" cheese whey, the difference was significant, even after the adjustment.
\end{abstract}

Keywords: cheese whey, composition, infrared milk analyzer 


\section{AGRADECIMENTOS}

Ao CNPq, à FAPEMIG, à CAPES e ao Laboratório de Análise da Qualidade do Leite/Escola de Veterinária da UFMG/FUNDEP.

\section{REFERÊNCIAS BIBLIOGRÁFICAS}

BENTLEY Instruments, Inc. Bentley Sistema Combinado 2300. Operator's manual. Chaska: Bentley, 2007. 115p

BIGGS, D.A.; JOHNSSON, G.; SJAUNJA, L.O. Analysis of fat, protein, lactose and total solids by infrared absorption. In: Monograph on rapid indirect methods for measurement of the major components of milk. Bull. Int. Dairy Fed. Standard, n. 208, p.21-29, 1987.

BOUIS, P. Qualitative optical spectroscopic methods. In: SETTLE, F. (Ed). Handbook of Instrumental techniques for analytical chemistry> New Jersey: Prentice-Hall, 1997. p.243-283.

BRASIL. Ministério da Agricultura, Pecuária e Abastecimento. Instrução normativa n.68, de 12 de dezembro de 2006: Métodos analíticos oficiais físico-químicos para controle de leite e produtos lácteos: Métodos quantitativos. Brasília, DF: Ministério da Agricultura, Secretaria de Defesa Agropecuária.

ETZION, Y.; LINKER, R.; COGAN, U. et al. Determination of protein concentration in raw milk by mid-infrared Fourier transform infrared/attenuated total reflectance spectroscopy. $J$. Dairy Sci., v.87, p.2779-2788, 2004.
OFFICIAL methods of analysis. 16.ed. Washington: AOAC, 1997.

SILVA, P.I. Métodos de extração e caracterização de bixina e norbixina em sementes de urucum (Bixa orellana L.). 2007. 145f. Dissertação (Mestrado em Ciência E Tecnologia de Alimentos) Universidade Federal de Viçosa, Viçosa, MG.

SILVEIRA, T.M.L. Comparação dos métodos de referência e de análise eletrônica na determinação da composição e da contagem de células somáticas do leite bovino. 2002. 42f. Dissertação (Mestrado em Medicina Veterinária) - Escola de Veterinária, Universidade Federal de Minas Gerais, Belo Horizonte.

SOUZA, E.C. Estudo químico e físico-químico dos pigmentos do urucum (Bixa orellana) utilizando metodologia simplificada de extração. 2000. 45f. Dissertação (Mestrado em Ciências dos Alimentos) - Universidade Federal de Lavras, Lavras, MG.

TEIXEIRA, L.V.; FONSECA, L.M. Perfil físicoquímico do soro de queijos mozarela e minaspadrão produzidos em várias regiões do estado de Minas Gerais. Arq. Bras. Med. Vet. Zootec., v.60, p.243-250, 2008. 